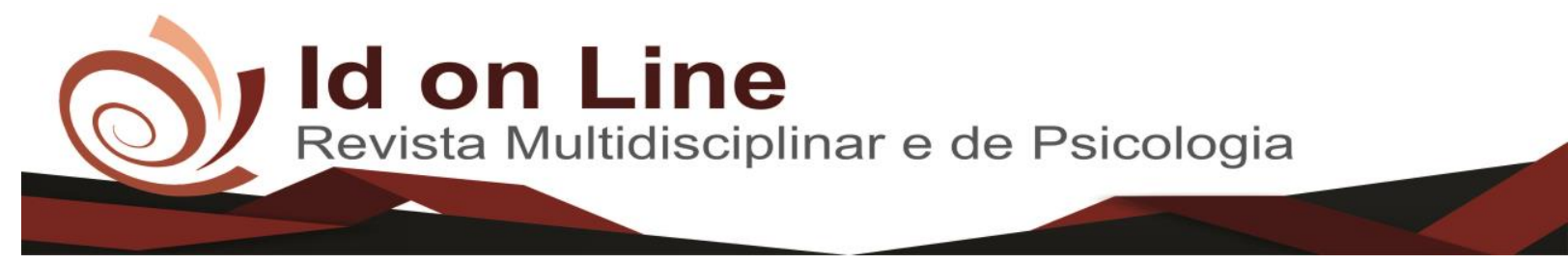

Artigo

\title{
Controle Interno como Ferramenta Essencial contra Erros e Fraudes nas Entidades
}

\author{
Ingli Helen Nogueira ${ }^{1}$; Maria Erilúcia Cruz Macedo ${ }^{2}$
}

\begin{abstract}
Resumo: Diante da globalização, as entidades sentiram a carência em aprimorar seus procedimentos internos usados na produção de bens ou serviços e na proteção dos seus ativos com o desígnio de se sobreviver na presença do mercado competitivo. O sistema de controle interno é uma ferramenta de suma importância para o desenvolvimento das organizações, pois atuante no auxílio à gestão assim como na proteção do patrimônio da entidade. Os distintos subsistemas do controle interno agem em cada departamento para especificar a visão do comportamento da entidade como de sua totalidade. Este estudo teve como propósito reconhecer o desenvolvimento organizacional através da utilização dos sistemas de controles interno hábeis. A metodologia utilizada foi bibliográfica, onde através do referencial teórico. Diante das pesquisas observou-se que há um déficit de desempenho nos controles internos, carecendo de melhorias, em alguns aspectos, como por exemplo, na segregação de funções, incremento de treinamento para os colaboradores e no controle de seus ativos. Sendo perceptível que, controles internos eficientes contribuem diretamente para uma excelente prática das atividades diárias da entidade e impulsiona o desenvolvimento da mesma.
\end{abstract}

Palavras-chave: Controles internos, Ferramenta, Desenvolvimento Organizacional.

\section{Internal Control as an Essential Tool against Errors and Fraud in Entities}

\begin{abstract}
In the face of globalization, the entities felt the lack of improving their internal procedures used in the production of goods or services and the protection of their assets with the intention of surviving in the presence of the competitive market. The internal control system is a tool of paramount importance for the development of organizations, since it acts in aid to the management as well as in the protection of the patrimony of the entity. The different subsystems of the internal control act in each department to specify the vision of the behavior of the entity as of its totality. This study aimed to recognize organizational development through the use of skillful internal control systems. The methodology used was bibliographical, where through the theoretical reference. In the face of the research, it was observed that there is a performance deficit in the internal controls, lacking in some aspects, such as segregation of duties, increased training for employees and control of their assets. It is noticeable that efficient internal controls directly contribute to an excellent practice of the entity's daily activities and impels the development of the same.
\end{abstract}

Keywords: Internal controls, Tool, Organizational Development.

\footnotetext{
${ }^{1}$ Centro Universitário Doutor Leão Sampaio. UNILEÃO. Juazeiro do Norte, Ceará, Brasil.

${ }^{2}$ Administradora. Professora no Centro Universitário Doutor Leão Sampaio. UNILEÃO. Juazeiro do Norte, Ceará, Brasil. Pesquisadora na área de estratégia e comportamento do consumidor. Contato: erilucia@leaosampaio.edu.br
} 


\section{Introdução}

A esfera atual do mercado competitivo exige que as empresas disponham de técnicas que forneçam informações eficientes e precisas para expandirem suas operações de modo adequado, fazendo com que a entidade cumpra com as metas estabelecidos pela gestão organizacional.

O sistema de controle interno é uma ferramenta que tem por obrigação favorecer o processo instrutivo da entidade para que os métodos determinados sejam cumpridos de modo competente, para assim nortear os gestores nas suas tomadas de decisões.

O fato é que muitas organizações vêm utilizando-se de controles internos ineficientes ou ineptos às suas atividades, e isso tem levado os gestores a se basearem em informações que não retratam a realidade de suas entidades, tomando assim decisões que comprometam o desenvolvimento e a continuidade empresarial.

Diante disso, se faz necessário um estudo sobre o tema uma vez que, o sistema de controle interno se compromete a produzir informações fidedignas e relatórios íntegros que transfiram aos gestores confiabilidade sobre as atividades que estão sendo desenvolvidas e assim prosseguir à continuidade empresarial.

O presente trabalho foi norteado a partir da curiosidade em descobrir como o controle interno pode findar com erros e fraudes dentro das entidades. $\mathrm{O}$ fato é que, os diversos subsistemas do controle interno devem ser atuantes nos setores das empresas e auxiliarem nas fiscalizações do fiel cumprimento das atividades determinadas para cada departamento, facilitando assim o controle de todas as áreas da empresa, assim promovendo mais confiabilidade nas informações.

A metodologia utilizada foi a pesquisa exploratório de cunho bibliográfico, onde buscou-se fundamento na literatura sobre os controles internos como ferramenta contra erros e fraudes.

\section{Referencial Teórico}

\section{Controladoria}

Segundo Padoveze (2003, p. 3), a controladoria é uma ciência independente que se utiliza do conjunto da doutrina contábil dentro da organização. A controladoria é a ciência 
responsável pela projeção e aplicação de métodos, pois a contabilidade é a ciência de todos os acontecimentos temporários sendo: passado, presente e futuro, em comum acordo com os demais.

A controladoria é uma área que atualmente tem uma importância inenarrável no âmbito de negócios, por sua totalidade de desempenho, pois se moldam às necessidades e aos requisitos de cada entidade, onde se adequa para planejamento e controle dos negócios (MORANTE, 2008).

De acordo com Almeida (1999) aponta que uma cisão do conceito de Controladoria em dois vértices:

O primeiro como ramo de conhecimento responsável pelo estabelecimento de toda a base conceitual, e o segundo como órgão administrativo respondendo pela disseminação de conhecimento, modelagem e implantação de sistemas de informações.

Seguindo tal pensamento, têm-se como ramo de conhecimento a doutrina contábil que é a teoria primordial para a estrutura de um sistema de informações que dê suporte instrumental ao gestor em seu processo de gestão

O conceito de controladoria é dividido em dois aspectos: o primeiro consiste como ramo de instrução responsável pela entidade e toda a origem conceitual, e segundo como parte administrativa consciente de toda inerência de conhecimento, modelagem e implantação de sistemas de informação. Percebe-se uma acessão pela contabilidade, e enfatizando a progressão na busca pela área denominada controladoria, que pertence à ciência contábil seguindo seus princípios e os fundamentos da gestão empresarial (Schmidt, et al.,2014).

De acordo, Padoveze (2012) entende-se que o ofício da controladoria compõe-se nas funções de reporte de dados e nos registros, com aplicabilidade aos seus propósitos que são: controle e proteção dos seus ativos, voltados aos dados; controle de ativos com entrada e saída de caixa, acompanhamento e análise de todos os ativos da empresa de forma a protegê-los contra perdas ou fraudes; cumprimentos das obrigações fiscais, que requer obrigações fiscais com melhor planejamento tributário; planejamento e controle das operações, missão desse propósito fiscais vem colaborar com a formulação de políticas, enfatizando os dados planejados na forma orçamentária desejada.

Ao analisar Nascimento (2015) percebe-se que a controladoria desenvolve um avanço na sua execução, pois onde antigamente era retratado apenas no tradicionalismo de gestão e produção, com a globalização ganha um total controle de qualidade, proporcionando ampla modificações. A partir da globalização, a contabilidade gerencial progrediu, pois manifestouse a carência de uma proporção maior e detalhada de informações para a administração das 
empresas, viabilizando um procedimento de decisões convicto e seguro, fundado por elementos de controle interno e externos às entidades que retratem as suas orientações.

A partir desta proporção surge uma crescente ascensão à importância da Contabilidade gerencial, gerando a evolução dos sistemas de controles gerenciais na mesma proporção do crescimento das grandes corporações de diversificadas atividades.

\section{Missão e Função}

A Controladoria apropria-se de uma função de assessoria do gestor principal da organização, possuir o compromisso pela entidade de um sistema de controles que proporcione a atuação administrativa. Tem como missão "zelar pela continuidade da empresa, assegurando a otimização do resultado global” (FIGUEIREDO; CAGGIANO, 2004).

A principal atividade da controladoria é gerar atividades internas, na expectativa de obtenção de resultados positivos para a entidade, mediante avaliação pelo seu desempenho por intermédio dos resultado obtidos, onde a ação da controladoria não se confunde com outras ações da ciência contábil, dado que no contexto social o sistema organizacional é dinâmico e flexível para compor os diversos níveis hierárquicos de uma entidade, dando importância a evolução do impacto que a competição mundial proporciona à gestão das empresas, a globalização destaca a grandeza de avanços e conquistas tecnológicas e social que afetam diretamente esse crescimento, sendo ciente da cultura da empresa na iminência da formação de equipes engajadas em busca pela qualidade.

Embora a maior parte das informações repassadas para a controladoria seja de origem contábil, a atuação da controladoria não está circunscrita a administrar o sistema contábil da organização, tendo assim como papel fundamental zelar pela continuidade da empresa, viabilizando as sinergias existentes dentre os diversos departamentos da entidade, comparando a relevância dos resultados obtidos, com o intuito de proteger os ativos.

O profissional desta carreira denomina-se controller, que significa conforme destaca Bermudo o controller exerce autoridade de linha em seu próprio departamento, mas com a sua influência na organização "impele a administração rumo as decisões lógicas, consistentes com os objetivos" (BERMUDO, 2016).

Com o crescente avanço das entidades, abdicando a níveis hierárquicos e eminente das operações diárias, à frente da indispensabilidade de agrupar estrategicamente, a entidade centralizou numa parte intrínseca as funções de controladoria. Com a proposta de distinguir e 
referir a direção gestora e seus respectivos órgãos as possíveis dificuldades da atualidade e as adivinhas que encontram-se envolvendo ou venham a envolver e comprometer a rentabilidade da entidade.

Identifica-se que para desempenho da performance da Controladoria, seu seção específica necessita denominado pela (o), segundo Padoveze (2006), a produção e preservação do plano integrado para o exercício do controle; a avaliação do desempenho organizacional baseado nos projetos e modelos estabelecidos; a relação e análise dos resultados obtidos; a aplicação de procedimentos e técnicas que guiem ao alcance de das políticas e dos objetivos do negócio, a organização de controles internos com a finalidade de proteção dos ativos da entidade.

Sendo assim entende-se que a controladoria tem como missão coordenar esforços junto aos gestores das entidades com vista a garantir o cumprimento da missão, visão e valores da entidade viabilizando a sua continuidade, com o total apoio no processo de tomada de decisões, acerca da coleta e geração de informações fidedignas e tempestivas, ofertando assim aos gestores meios de obtenção de um resultado global, coerente com as metas estipuladas, buscando desta forma prosseguir com a vitalidade da organização.

Conforme Peleias (2012) a controladoria conduz como órgão de observação o controle da central administrativa da entidade contribui para o processo de gestão empresarial fornecendo subsídios à etapa de planejamento, com informações e instruções que permitem aos gestores avaliarem o impacto das diversas alternativas de ações sobre o patrimônio da entidade e os resultados da organização, à etapa de execução, por meio de informação que permitam comparar os desempenhos reais nas condições padrão e realizado e à etapa de controle, permitindo a comparação das informações relativas à atuação dos gestores e áreas de responsabilidade relativamente a planos e padrões previamente estabelecidos.

\section{Controle Interno}

Uma das ferramentas que operativa à assegurar que as entidades adquiram o progresso convincente é a utilização de controle interno que executa indicadores frequentes para assegurar resultados suficientes no ciclo operacional das entidades, com propósito de de proteger e preservar os bens e direitos, fomentando dados contábeis fidedignos que subsidiaram os gestores em suas tomadas de decisões. 
Sendo um dos meios eficaz que venha a assegurar que a entidade obtenha o avanço satisfatório é com a utilização da ferramenta de controle interno que executa medidas constantes para garantir resultados eficientes no ciclo operacional das entidades, com o intuito de proteção de seus ativos e salvaguardar os bens e direitos, produzindo assim dados de confiabilidade que auxiliarão os gestores nas suas tomadas de decisão.

Controle interno é um instrumento imprescindível para uma entidade, pois um sistema contábil eficiente depende do êxito do controle interno, sendo o mesmo vital para evolução da organização, a carência do mesmo gerá dados contábeis sem exatidão e sem fidedignidade.

Segundo Crepaldi (2007, p.276), "pode-se entender a importância de controle interno a partir do momento em que se verifica que é ele que pode garantir a continuidade do fluxo de operações com as quais convivem as empresas."

Desta forma, o controle interno deve averiguar se os saldos que aumentam a confiabilidade e a exatidão dos dados contábeis para a entidade podem assegurar se as metas designadas pelos gestores estão sendo cumpridas de acordo com o planejamento da gestão organizacional, produzindo dados confiáveis e dando base para a condução de seus negócios.

Os controles internos nas entidades têm diversas atribuições, em razão de que é uma sustentação para os processos decisórios, põem visto que norteiam o uso das ferramentas atribuídas aos gestores, para averiguação da destinação correta dos ativos, para cumprimento do princípio da entidade, no qual não se pode utilizar-se dos bens, direitos ou obrigações da empresa para com a pessoa física.

Na visão de Attie (1998, p. 144), o controle contábil inclui o plano de organização e de forma geral todos os métodos e procedimentos diretamente relacionados basicamente a salvar o patrimônio da entidade e a fidedignidade dos registros contábeis.

Os controles internos na gestão organizacional visam fornecer a eficiência operacional seguindo seus métodos e procedimentos a fim de extinguir erros e fraudes, cessando as perdas e adquirir lucros, através das instruções da controladoria.

\section{Os Controles Internos e Fraudes}

A extração de relatório inconsistentes estão sujeitos a algum tipo de ameaças, apresentando a falta de confiabilidade e a inexatidão nas informações. Com a introdução de um sistema de controle interno pode-se impedir a ocorrência de fraudes, a falta de controle efetivo 
em alguns departamentos considera-se áreas de risco possibilitando a existência de situações inadequadas.

De acordo com Almeida (2007) existem algumas formas de avaliar a segurança do controle interno, onde é necessário compreender os seguintes pontos: conhecer erros ou irregularidades que possam vir a acontecer; verificar se o sistema detecta em tempo hábil caso haja erros ou irregularidades; analisar as limitações do sistema de controle interno ou a falta do mesmo, a fim de determinar natureza, data e extensão dos procedimentos de auditoria; emissão de relatório com análises e críticas construtivas para aprimoramento do sistema de controle interno da entidade.

A implantação do controle interno em todos os setores da entidade pode diminuir os desperdícios e certificar que os resultados esperados sejam obtidos, e a todo tempo permitindo reconhecer e identificar regularidades existentes nas atividades operacionais.

Conforme Conselho Federal de Contabilidade (2008. p. 59) "O termo fraude refere-se ao ato intencional de omissão ou manipulação de transação, adulteração de documentos, registros e demonstrações contábeis."

Fraude é um crime doloso, pois refere-se ao ato intencional do indivíduo que articula produzir alterações à uma realidade diferente, podendo beneficiar a si mesmo ou a medidores interessados.

\section{Os Controles Internos e Erros}

Um controle interno em si não é o suficiente para a inexistência de fraudes e erros. Ele funciona para detectar todas as ações ocorridas pelos funcionários, porém ainda é existente um despreparo da parte dos funcionários para a execução de suas atividades.

De acordo com as normas de auditoria independente das demonstrações contábeis, NBC T 11, item 11.1 .4.1 (1997): "Erro, é o ato não intencional resultante de omissão, desatenção ou má interpretação de fatos na elaboração de registros e demonstrações contábeis". Ou seja, erro é uma ação não intencional, em geral é perceptível que o mesmo acontece por falta de preparo ou por falta de habilidade técnica do responsável pelo controle.

A medida que a empresa controla as informações, se possuírem código de ética e disponibilizarem um treinamento apto capacitando seus funcionários, através de normas, técnicas e procedimentos, o índice de erros e fraudes ou fatos dessa natureza serão instantaneamente reduzidos. 
Para Franco e Marra (2001, p. 215) eles definem erros e fraudes sendo: “ Muitos erros e fraudes são dissimulados na escrituração enquanto outras irregularidades, praticadas contra o patrimônio , não são contabilizadas, somente podendo ser apuradas por ocasião de conferência física dos valores patrimoniais"

Por tanto, um sistema de controle interno deve identificar tais irregularidades para que assim sejam aplicadas sua devida correção. Entretanto, até mesmo o melhor sistema interno ainda pode ser ludibriado com a ação humana dentro de uma entidade.

\section{Fraudes e Erros}

A distinção entre fraude e erro está no fato de erro ser involuntário, pois quando cometido o indivíduo que o comete age sem intenção de ocasionar o dano. O erro é, segundo Sá (2002, p. 22), ”(...) fruto da desídia ou ignorância, neste caso considerado como invito; são os ilícitos denominados culposos e tem sua origem na negligência, imperícia, imprudência e desídia".

A fraude é uma junção de intencionalidade e premeditação, com o objetivo de causar dano, por isso configura-se crime doloso, ou seja, quando existe a intenção de prejudicar outrem ou para favorecimento próprio ou de terceiros.

Segundo a NBC T11 (199) define fraude e erro:

Fraude: o ato intencional de omissão ou manipulação de transações, adulteração de demonstrações contábeis; e.

Erro: o ato não intencional resultante de omissão, desatenção ou má interpretação de fatos na elaboração de registros e demonstrações contábeis.

Existe alguns parâmetros que levam a ocasionar fraude e erro, embora sejam distintos um do outro, porém um sistema interno ineficiente ou uma fiscalização omissa, são categorizadas como rupturas de um sistema interno, onde o indivíduo percebe tais rupturas e intencionalmente comete a fraude, o erro só irá agravar ainda mais essas rupturas desse sistema interno.

A justificativa do fraudador reside na busca por redimir seus atos, querendo assim se isentar da culpa e adotando uma hombridade que não se configura a ele e depositando também à terceiros. 


\section{Importância de Segregação de Funções}

Um dos principais elementos de suporte para preservar os interesses das entidades é a segregação de funções, sendo uma prática contínua do controle interno que divide a atividade dos funcionários, deste modo controlando as ações executadas.

Segundo Almeida $(2009$, p.7) retrata que a segregação de funções determina que uma mesma pessoa não tenha acesso aos ativos e aos registros contábeis, devido a tais funções são incompatíveis dentro do sistema de controle interno. Como exemplo pode-se citar que a pessoa que responsável por receber dinheiro em caixa não pode ser responsável pelo pagamento das contas, sendo assim as responsabilidades e funções devem ser divididas e definidas para que nenhum funcionário seja responsável por controlar todas as etapas de uma operação ou processo de transação.

Deste modo, para impossibilitar que os funcionários trabalhem na integralização de duas ou mais funções, a segregação de funções que necessitam ser divididas por partes e cada parte apropriada fiscalização de tal forma que o trabalho de um funcionário seja fiscalizado por outro sendo assim todas as etapas de um processo serão monitoradas, dificultando assim atos fraudulentos e possíveis erros.

De acordo com Attie (1999) essas divisões de obrigações são concernentes a um bom controle interno, no qual estabelece que as atividades de iniciar até a etapa de autorizar devem ser executadas separadamente por funcionários distintos dos que farão suas contabilizações. Da mesma forma que a guarda de bens patrimoniais estejam separados de sua contabilização.

Logo o responsável por gerar informações não as controla, sendo assim a segregação de funções define os padrões que previnem os erros intencionais e os não intencionais que são de suma importância para o desenvolvimento de um adequado sistema interno.

\section{A Contribuição dos Controles Internos para o Desenvolvimento Organizacional}

O sistema de controle interno é uma ferramenta cujo um dos principais objetivos é dar suporte à gestão organizacional na tomada de decisões, com o intuito de promover melhorias nos resultados, visando a importância da integridade e tempestividade das informações para que assim as decisões surtam efeito tanto em tempo hábil como na área correta.

Segundo Oliveira, Perez Jr. e Silva (2011, p. 70) eles abordam que é de fundamental importância saber a qualidade e o grau de confiabilidade dos sistemas de controles internos 
desde a fase inicial de planejamento de seus trabalhos, para que ocorra a identificação exata das áreas de risco.

Diversos fatores precisam ser levados em consideração, para que o sistema de controle interno contenha informações confiáveis, uma vez que para a produção dessas informações há o envolvimento de diversos funcionários de distintos departamentos, recursos, estratégias e políticas organizacionais. É necessário levar em consideração a ação organizacional demonstrada na figura abaixo:

Figura 1 - Dimensōes do controle organizacional

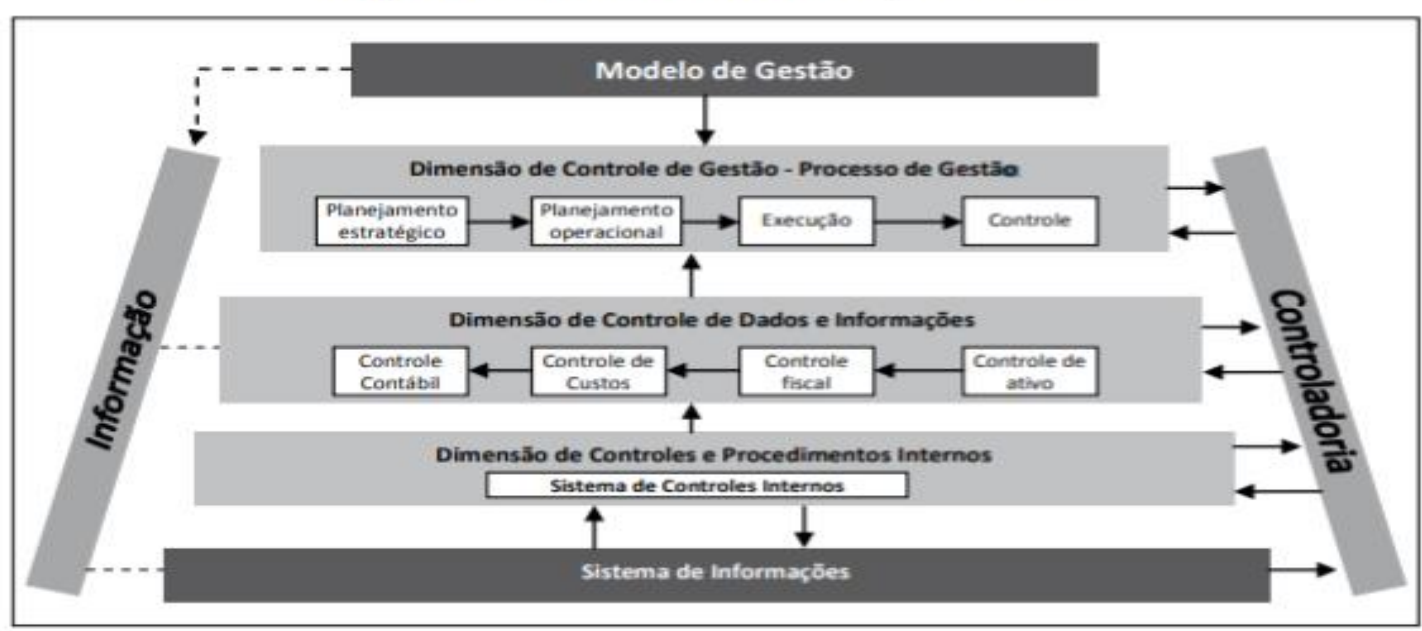

Fonte: Nascimento e Reginato (2013, p. 5).

Nascimento e Reginato (2011) explicam as dimensões do controle organizacional, como sendo a incorporação de elementos, destacando os planejamentos existente de controle organizacional, que são provindos da controladoria que é a responsável por nortear e discimificar os controles existentes, ainda sobre as dimensões de controle de dados da informação ou seja, os produtos ou serviços ofertados pela empresa foram os resultados de pessoas, que utilizam de tecnologia adaptada para a realização de tais tarefas. A tecnologia e as pessoas são recursos utilizados pela empresa e são organizados sobre determinada estrutura organizacional, onde visa garantir a eficácia organizacional. Tais dimensões do controle organizacional é o conjunto que aloca dentro de uma estrutura física, recursos que através de técnicas, procedimentos e tecnologia executarão tarefas que resultarão em produtos e serviços, seguindo assim, os objetivos da entidade serão alcançados.

Sendo indispensável conceber uma empresa que não provém de um controle interno, pois se torna impossível uma entidade que não disponha de controle interno que possam atestar 
a continuidade do fluxo de operações e informações propostas. Para que os controles internos cooperem para alavancar o desenvolvimento da entidade é necessário que eles sejam adequados à organização e a todos os procedimentos que a compõem e que desenvolvidos com o intuito de obtenção das metas preestabelecidas.

Primeiramente e faz necessário analisar toda a estrutura da entidade, pois a mesma influenciará diretamente nos procedimentos de controle interno que serão adotados, quanto maior a estrutura da entidade mas complexo e rigoroso será o sistema de controles internos. Por outro lado e, não menos importante, um dos aspectos relevantes também é a tecnologia utilizada, principalmente no que se diz respeito ao sistemas de informações adotados devendo ser confiáveis e seguros, assim como os acessos a essas informações devem ser delimitados.

Com relação às tarefas executadas, os controles internos devem salientar a segregação de funções, pois se faz necessário que cada membro da entidade tenha total conhecimentos sobre as atividades que devem executar para que não haja dúvidas quanto às suas responsabilidade, evitando primordialmente que todas as ações da entidade sejam executadas por uma única pessoa, garantindo assim confiabilidade em todos os processos.

Portanto, os controles internos necessitam avaliar as dimensões do controle organizacional para que sejam determinados os métodos e procedimentos condizentes com as características do ambiente organizacional e cada ação seja examinada para que os processos possam ser revisados e aperfeiçoados.

Sendo assim, os controles internos colaboram para que todas as áreas da entidade interajam de modo sinérgico, desse modo, o desenvolvimento organizacional é notório nos resultados, visto que todos os procedimentos sejam realizados com a máxima eficácia, detectando os desperdícios e as perdas e principalmente impedindo irregularidades, desta forma aumentando a lucratividade da empresa, além do mais, as informações elaboradas pelos controles internos configuram aos gestores confiança nas decisões que garantirão a continuidade da organização.

\section{Metodologia}

O presente trabalho foi desenvolvido através de pesquisa bibliográfica, quanto a natureza, é caracterizada como exploratória, de forma a enfatizar o máximo de informações sobre o tema que salienta o papel do controle interno como ferramenta contra erros e fraudes nas entidades, onde baseou-se em livros, normas contábeis e periódicos, bem como na internet. 
Para Gil (2009):

\begin{abstract}
A pesquisa bibliográfica é desenvolvida com base em material já elaborado, constituído principalmente de livros e artigos científicos. A principal vantagem da pesquisa bibliográfica reside no fato de permitir ao investigador a cobertura de uma gama de fenômenos muito mais ampla do que poderia pesquisar diretamente.
\end{abstract}

Tratando de uma pesquisa descritiva-exploratória, onde o objetivo foi descrever, analisar e aprimorar as ideias sobre o tema, possibilitando a consideração dos mais variados aspectos relativos a esse estudo.

A caracterização da pesquisa é qualitativa, uma vez que foi analisado a concentração teórica e as diversas linhas de pensamentos dos estudos do assunto.

\title{
Considerações Finais
}

A pesquisa mostrou a importância do papel do controle interno como ferramenta essencial contra erros e fraudes nas entidades; procurou-se reforçar pontos importantes mostrando a capacidade e eficiência que o mesmo possui, em diversos aspectos e primordialmente para a assegurar a integridade do patrimônio da empresa.

Desta forma o controle interno exerce uma organização o conjunto de mecanismos, técnicas, métodos e práticas com o intuito de proteger os ativos. Com a sua utilização é muito provável que se tenha a maior confiabilidade nos documentos da entidade em questão e possibilitando assim a entidade a atuar com maior rapidez e segurança possível nas tomadas de decisões.

Um ponto importante para ser destacado no controle interno é a segregação de funções que contribui diretamente para a eficiência das operações e identifica, em tempo hábil, fraudes e erros que poderão acontecer de um funcionário para tentar se beneficiar ou beneficiar a outrem, prejudicando assim a empresa. Por este motivo é fundamental importância limitar as tarefas entre os setores, onde as atividades realizadas são automaticamente fiscalizadas por outra pessoa. Visto também que é necessário conhecer profundamente a necessidade que a entidade tem para extrair informações e utilizá-las para traçar os melhores métodos que sejam capazes de contribuir com o crescimento e desenvolvimento da entidade.

Pode-se concluir que há uma ampla carência de mais estudos e discussões sobre o tema exposto no presente trabalho, onde os gestores devem tratar o controle interno como ferramenta que possa contribuir para a vitalidade, desenvolvimento e crescimento da entidade. 


\section{Referências}

ALMEIDA, Marcelo Cavalcanti. Auditoria: Um curso moderno e completo. 6 ed. São Paulo.Atlas, 2007.

BERMUDO, Roberto Vera, Vertamatti. Controladoria estratégica e seus desdobramentos comportamentais: a SOX como apoio à geração de valor organizacional. São Paulo: Atlas, 2016.

CREPALDI, Silvio Aparecido. Contabilidade Gerencial: teoria e prática - 4 ed.São Paulo: Atlas, 2007

FIGUEIREDO, Sandra; CAGGIANO, Paulo Cesar. Controladoria, teoria e prática. São Paulo: Atlas, 2004.

FRANCO, Hilário; MARRA, Ernesto. Auditoria contábil. 4 ed. São Paulo: Atlas,2001

GIL, Antonio Carlos. Métodos e técnicas de pesquisa social. São Paulo: Atlas, 200

MORANTE, Fauzi Timaco Jorge,Antonio Salvador. Controladoria: análise financeira, planejamento e controle orçamentário. São Paulo :Atlas, 2008.

NASCIMENTO, Auster Moreira, REGINATO Luciane. Controladoria Instrumento de apoio ao processo decisório -- 2. ed. -- São Paulo: Atlas, 2015.

NASCIMENTO, Auster Moreira, REGINATO Luciane; SOUZA, Marcos Antônio. Planejamento Operacional In: Controladoria: um enfoque na eficácia organizacional. São Paulo: Atlas, 2007.

NBC, Normas brasileiras de contabilidade. NBC T.11.1.4.1. Normas de auditoria independente das demonstrações contábeis. Portal de contabilidade: Brasília, 17 de dezembro de 1997. Disponível em: 〈http://www.portaldecontabilidade.com.br/nbc/t11.htm>. Acesso em 14 de outubro de 2018.

PADOVEZE, Clóvis Luís. Controladoria Estratégica e Operacional. $3^{\mathrm{a}}$ ed. São Paulo: Cengage Learning, 2012

PADOVEZE, Clóvis Luís. Controladoria Estratégica e Operacional. São Paulo: Thomson,2003.

PADOVEZE, Clóvis Luís. Curso Básico Gerencial De Custos - 2 ed São Paulo: Thomson,2006.

PELEIAS, Ivam Ricardo. Controladoria: gestão eficaz utilizando padrões. São Paulo, Saraiva, 2002

SÁ, A. L. de. Curso de Auditoria. 10. ed. São Paulo: Atlas, 2002. 
SCHMIDT, Paulo José Luiz dos Santos, Marco Antônio dos Santos Martins.Manual de controladoria-São Paulo: Atlas, 2014.

\section{Como citar este artigo (Formato ABNT):}

NOGUEIRA, Ingli Helen; MACÊDO, Maria Erilúcia Cruz. Controle Interno como Ferramenta Essencial contra Erros e Fraudes nas Entidades. Id on Line Rev.Mult. Psic., 2019, vol.13, n.43, p. 670-683. ISSN: 1981-1179.

Recebido: 13/11/2018;

Aceito: $21 / 11 / 2018$ 